Situs Jurnal : $\underline{\text { http://ejournal.stiepancasetia.ac.id/index.php/jieb }}$

Jilid 7 Nomor 1 Maret 2021

Hal 136-147

\title{
PENGARUH BUDAYA KERJA, KEPUASAN KERJA, DAN MOTIVASI KERJA TERHADAP KINERJA KARYAWAN DI ERA PANDEMI COVID-19 PADA PT. PATRIOT INTAN ABADI FARM BERLIAN KECAMATAN BATI - BATI
}

\section{Arifia Nurriqli, Ginanjar Wahyudi}

\begin{abstract}
Abstrak: Tujuan dari penelitian ini 1) Untuk mengetahui pengaruh secara Simultan Variabel Budaya Kerja, Kepuasan Kerja, dan Motivasi Kerja Terhadap Kinerja Karyawan Di Era Pandemi Covid-19 Pada PT. Patriot Intan Abadi Farm Berlian Kecamatan Bati-Bati. 2) Untuk mengetahui pengaruh secara Parsial Variabel Budaya Kerja, Kepuasan Kerja, dan Motivasi Kerja Terhadap Kinerja Karyawan Di Era Pandemi Covid-19 Pada PT. Patriot Intan Abadi Farm Berlian Kecamatan Bati-Bati. 3) Untuk mengetahui Variabel manakah yang berpengaruh secara dominan diantara tiga variabel bebas yaitu variabel Budaya Kerja, Kepuasan Kerja, dan Motivasi Kerja Terhadap Kinerja Karyawan Di Era Pandemi Covid-19 Pada PT. Patriot Intan Abadi Farm Berlian Kecamatan Bati-Bati.
\end{abstract}

Jenis Penelitian yang digunakan adalah penelitian penjelasan (explanatory research) dengan pendekatan kuantitatif. Sampel yang digunakan sebanyak 40 responden yaitu seluruh karyawan pada divisi Produksi, Teknik analisa data yang digunakan dalam penelitian ini adalah analisis regresi linear berganda, dengan menggunakan Uji F, Uji t dan Uji Variabel Dominan. Hasil regresi linear berganda penelitian sebelum Pandemi Covid-19, hasil Uji F menunjukkan nilai sig 0,005 < 0,05, yaitu bahwa sebelum pandemi covid-19 Variabel Budaya Kerja, Kepuasan Kerja, dan Motivasi Kerja secara Simultan berpengaruh signifikan terhadap Kinerja Karyawan. Hasil Uji t, pada variabel Budaya Kerja Menunjukkan nilai sig. 0,017 < 0,05, dengan ini variabel Budaya Kerja secara parsial berpengaruh signifikan terhadap Kinerja Karyawan. Variabel Kepuasan Kerja menunjukkan nilai sig. 0,353 > 0,05, dengan ini Variabel Kepuasan Kerja secara parsial tidak berpengaruh signifikan terhadap Kinerja Karyawan. Variabel Motivasi Kerja secara parsial berpengaruh signifikan terhadap Kinerja Karyawan dengan nilai sig. 0,034<0,05, dan variabel Motivasi Kinerja adalah variabel dominan dengan nilai Beta 0,32 yang mana nilai tersebut lebih besar dari nilai Beta Variabel Budaya Kerja dan Kepuasan kerja. Hasil regresi linear berganda penelitian sesudah Pandemi Covid-19, hasil Uji F menunjukkan nilai sig 0,003 < 0,05, yaitu bahwa sesudah Pandemi Covid-19 Variabel Budaya Kerja, Kepuasan Kerja, dan Motivasi Kerja secara Simultan berpengaruh signifikan terhadap Kinerja Karyawan. Hasil Uji t, pada variabel Budaya Kerja Menunjukkan nilai sig. 0,007 < 0,05, dengan ini variabel Budaya Kerja secara parsial berpengaruh signifikan terhadap Kinerja Karyawan. Variabel Kepuasan Kerja menunjukkan nilai sig. 0,585 > 0,05, dengan ini Variabel Kepuasan Kerja secara parsial tidak berpengaruh signifikan terhadap Kinerja Karyawan. Variabel Motivasi Kerja secara parsial berpengaruh signifikan terhadap Kinerja Karyawan dengan nilai sig. 0,019<0,05, dan variabel Motivasi Kinerja adalah variabel dominan dengan nilai Beta 0,34 yang mana nilai tersebut lebih besar dari nilai Beta Variabel Budaya Kerja dan Kepuasan kerja

Kata Kunci : Budaya Kerja, Kepuasan Kerja, Motivasi Kerja, Kinerja Karyawan 


\section{Latar Belakang}

Karyawan merupakan aset perusahaan yang sangat berharga yang harus dikelola dengan baik oleh perusahaan agar dapat memberikan kontribusi yang optimal. hal yang harus menjadi perhatian utama perusahaan adalah budaya kerja, kepuasan kerja, dan motivasi kerja karyawan. Budaya kerja, adalah sekumpulan pola perilaku yang melekat secara keseluruhan pada diri setiap karyawan dalam sebuah perusahaan. Membangun budaya berarti juga meningkatkan dan mempertahankan sisisisi positif, serta berupaya membiasakan pola perilaku tertentu agar tercipta suatu bentuk perilaku baru yang lebih baik dalam bekerja. Kemudian hal selanjutnya yang harus menjadi perhatian perusahaan adalah kepuasan kerja para karyawannya, karena karyawan yang dalam bekerja mereka merasa kurang puas terhadap gaji yang diterima, pekerjaannya, rekan kerja, promosi, lingkungan kerja, dan terhadap atasannya maka secara otomatis karyawan tidak dapat fokus dan berkonsentrasi secara penuh terhadap pekerjaannya. Karyawan tidak hanya sekedar melakukan pekerjaan, tetapi terkait juga dengan aspek lain seperti melakukan interaksi dengan teman kerja, atasan, mengikuti aturan - aturan dan lingkungan kerja tertentu yang seringkali kurang memadai atau kurang disukai. Kepuasan kerja pada dasarnya merupakan hal yang bersifat individual, setiap individu memiliki tingkat kepuasan yang berbeda - beda sesuai dengan keinginan dan sistem nilai yang dianut oleh individu, semakin tinggi tingkat kepuasan yang didapat. Demikian pula sebaliknya, semakin banyak aspek dalam pekerjaannya yang tidak sesuai dengan keinginan dan sistem nilai yang dianut individu, semakin rendah tingkat kepuasan yang didapat. Selain budaya kerja dan kepuasan kerja, perusahaan juga harus memperhatikan mengenai bagaimana menjaga dan mengelola motivasi karyawan dalam bekerja agar selalu tinggi dan fokus pada tujuan perusahaan. Karena motivasi merupakan sesuatu hal yang harus diperhatikan oleh perusahaan jika perusahaan ingin setiap karyawannya dapat bekerja dengan baik. Kinerja karyawan adalah tingkat seberapa tercapainya persyaratan - persyaratan pekerjaan yang telah dikerjakan oleh karyawan.

PT. Patriot Intan Abadi Farm Berlian Kecamatan Bati - Bati adalah salah satu perusahaan yang bergerak dalam bidang peternakan, khususnya peternakan ayam petelur.

Pandemi adalah epidemi yang terjadi pada skala yang melintasi batas internasional, biasanya memengaruhi orang dalam jumlah besar di dunia karena penyakit ini dapat menular dengan cepat. COVID-19 (coronavirus disease 2019) adalah penyakit yang disebabkan oleh jenis coronavirus baru yaitu Sars-CoV-2, yang dilaporkan pertama kali di Wuhan Tiongkok pada tanggal 31 Desember 2019.

Penelitian ini bertujuan untuk mengetahui pengaruh budaya kerja, kepuasan kerja, dan motivasi kerja karyawan di era pandemi COVID-19 pada PT. Patriot Intan Abadi Farm Berlian Kecamatan Bati-Bati secara simultan, parsial dan dominan.

\section{METODE PENELITIAN}

Metode Penelitian yang digunakan adalah penelitian penjelasan (explanatory research) dengan pendekatan kuantitatif. Sampel yang digunakan sebanyak 40 orang responden yaitu seluruh karyawan pada divisi produksi. Teknik analisa data yang digunakan dalam penelitian ini adalah uji Validitas, uji Reliabilitas, uji Asumsi Klasik dan analisis regresi linear berganda, dengan menggunakan Uji F, Uji t dan Uji Variabel Dominan.

\section{HASIL SEBELUM PANDEMI COVID-19}

1. Uji Asumsi Klasik

a. Uji Normalitas

Uji Normalitas Data bertujuan untuk memastikan data terdistribusi secara normal yaitu adalah tidak ada perbedaan yang signifikan antara data di atas mean dengan data di bawah mean. Uji Normalitas Data dilakukan menggunakan Uji KolmogorovSmirnov. Residual data dapat dinyatakan signifikan atau tidak normal jika nilai Asymp. Sig (2-tailed) kurang dari 0,05 begitu sebaliknya, jika nilai Asymp. Sig (2-tailed) lebih dari 0,05 
maka dinyatakan tidak signifikan yang artinya tidak terdapat ketidaknormalan pada residual data.

Tabel 1

Tabel Kolmogorov-Smirnov

\begin{tabular}{|l|l|l|}
\hline \multicolumn{2}{|l|}{} & \multicolumn{1}{|c|}{ RES1 } \\
\hline$N$ & & 40 \\
\hline \multirow{2}{*}{ Normal Parameters } & Mean & 0,00 \\
\cline { 2 - 3 } & $\begin{array}{l}\text { Std. } \\
\text { Deviation }\end{array}$ & 2,27 \\
\hline $\begin{array}{l}\text { Most Extreme } \\
\text { Differences }\end{array}$ & Absolute & 0,10 \\
\cline { 2 - 3 } & Positive & 0,09 \\
\cline { 2 - 3 } & Negative & $-0,10$ \\
\hline Kolmogorov-Smirnov Z & 0,63 \\
\hline Asymp. Sig. (2-tailed) & 0,826 \\
\hline
\end{tabular}

Sumber: Hasil Analisa PSPP (2021)

Dari Tabel di atas dapat dilihat bahwa nilai Asymp. Sig. (2-tailed) adalah sebesai 0,747 yang mana nilai tersebut lebih dari 0,05 . Dengan demikian berdasarkan dari kriteria pengujian kolmogorov-Smirnov, maka dinyatakan tidak terdapat ketidaknormalan pada residual data.

b. Uji Multikolinearitas

Uji Multikolinearitas bertujuan untuk memastikan bahwa didalam suatu model penelitian tidak terdapat variabel bebas yang berkorelasi terlalu erat dengan variabel bebas yang lain. Sebuah penelitian dinyatakan terdapat masalah Multikolinearitas jika korelasi antar variabelnya signifikan ( $\operatorname{sign}<0,05)$ dan koefisien korelasinya lebih dari $80 \%$ $(>0,8)$

Tabel 2

Tabel Uji Multikolinearitas (Correlation)

\begin{tabular}{|l|l|l|l|l|}
\hline \multicolumn{2}{|l|}{} & $\mathrm{X} 1$ & $\mathrm{X} 2$ & $\mathrm{X} 3$ \\
\hline $\mathrm{X} 1$ & Pearson Correlation & 1,00 &, 05 &, 23 \\
\hline & Sig. (2-tailed) & &, 738 &, 146 \\
\hline & N & 40 & 40 & 40 \\
\hline X2 & Pearson Correlation &, 05 & 1,00 &,- 19 \\
\hline & Sig. (2-tailed) &, 738 & &, 241 \\
\hline & N & 40 & 40 & 40 \\
\hline X3 & Pearson Correlation & 23 &,- 19 & 1,00 \\
\hline & Sig. (2-tailed) &, 146 &, 241 & \\
\hline & N & 40 & 40 & 40 \\
\hline
\end{tabular}

Sumber: Hasil Analisa PSPP (2021)

Dari table di atas dapat dilihat bahwa nilai korelasi Variabel Budaya Kerja (X1) dengan Kepuasan Kerja (X2) sebesar 0,05 (5\%) dan Sig (2-tailed) = 0,738, Variabel Budaya Kerja (X1) dengan Motivasi Kerja (X3) sebesar $0,23(23 \%)$ dan Sig (2-tailed) = 0,146, Variabel Kepuasan Kerja (X2) dengan Motivasi Kerja (X3) sebesar -0,19 (19\%) dan Sig (2-tailed) $=0,241$. Berdasarkan hasil analisis tersebut dapat dinyatakan bahwa penelitian ini tidak terdapat masalah multikolinearitas.

c. Uji Heterokedastisitas

Uji Heterokedastisitas bertujuan untuk memastikan bahwa tidak terdapat kesamaan variance residual antara suatu pengamatan ke pengamatan yang lain. Uji heterokedastisitas pada penelitian ini peneliti menggunakan Uji Glejser. Suatu model penelitian dinyatakan memiliki permasalahan heterokedastisitas jika terdapat pengaruh yang signifikan antara masing - masing variabel bebas dengan nilai abselut dari residual datanya atau dengan kata lain, yaitu jika nilai sig. kurang dari 0,05 maka dinyatakan terjadi masalah heterokedastisitas. Berikut adalah tabel dari hasil Uji Heterokedastisitas menggunakan Uji Glejser :

Tabel 3

Tabel Uji Glejser

\begin{tabular}{|c|c|c|c|c|c|}
\hline & \multicolumn{2}{|c|}{$\begin{array}{c}\text { Unstandardiz } \\
\text { ed } \\
\text { Coefficients }\end{array}$} & $\begin{array}{c}\text { Standardiz } \\
\text { ed } \\
\text { Coefficien } \\
\text { ts }\end{array}$ & t & Sig \\
\cline { 2 - 5 } & $\mathrm{B}$ & $\begin{array}{c}\text { Std. } \\
\text { Error }\end{array}$ & Beta & & \\
\hline $\begin{array}{c}\text { (Consta } \\
\text { nt })\end{array}$ & $\begin{array}{c}2,4 \\
2\end{array}$ & 3,31 &, 00 & - &, 73 \\
\hline X1 &, 03 &, 09 &, 06 & $\begin{array}{c}- \\
, 36\end{array}$ & $\begin{array}{c}, 71 \\
7\end{array}$ \\
\hline X2 &, 10 &, 06 &, 25 & $\begin{array}{c}1,5 \\
6\end{array}$ & $\begin{array}{c}, 12 \\
7\end{array}$ \\
\hline X3 &, 04 &, 03 &, 23 & $\begin{array}{c}1,4 \\
0\end{array}$ & $\begin{array}{c}17 \\
1\end{array}$ \\
\hline
\end{tabular}

Sumber: Hasil Analisa PSPP (2021)

Dari Tabel diatas diketahui bahwa variabel Budaya Kerja (X1) tidak berpengaruh secara signifikan terhadap nilai abselut dari residualnya ( $\mathrm{sig}=$ $0,717>0,05$ ), pada variabel Kepuasan Kerja (X2) tidak berpengaruh signifikan terhadap nilai abselut dari residualnya 
$(\operatorname{sig}=0,127>0,05)$, dan pada variabel Motivasi Kerja (X3) tidak berpengaruh signifikan terhadap nilai abselut dari residualnya $(\operatorname{sig}=0,171>0,05)$. Dari nilai yang telah diperoleh tersebut maka penelitian tersebut dinyatakan tidak terjadi masalah heterokedastisitas.

2. Analisis Regresi Linear Berganda

Dalam penelitian ini Analisis Regresi Linear Berganda digunakan untuk mengetahui hubungan dan pengaruh variabel Budaya Kerja (X1), variabel Kepuasan Kerja (X2), dan variabel Motivasi Kerja (X3) terhadap variabel Kinerja karyawan (Y) PT. Patriot Intan Abadi Farm Berlian. Persamaan regresi linear berganda adalah sebagai berikut: $\mathrm{Y}=$ $\alpha+\beta 1 \mathrm{X} 1+\beta 2 \mathrm{X} 2+\beta 3 \mathrm{X} 3+\mathrm{e}$

Hasil perhitungan Regresi Linear Berganda dapat dilihat pada Tabel berikut:

Tabel 4

Tabel Uji Regresi Linear Berganda

\begin{tabular}{|c|c|c|c|c|c|}
\hline & \multicolumn{2}{|c|}{$\begin{array}{c}\text { Unstandardized } \\
\text { Coefficients }\end{array}$} & $\begin{array}{c}\text { Standardized } \\
\text { Coefficients }\end{array}$ & \multirow{2}{*}{$t$} & \multirow{2}{*}{ Sig. } \\
\cline { 2 - 5 } & $\mathrm{B}$ & $\begin{array}{c}\text { Std. } \\
\text { Error }\end{array}$ & Beta & & \\
\hline (Constant) & 11,61 & 5,25 &, 00 & 2,21 &, 033 \\
\hline $\mathrm{X} 1$ &, 34 &, 14 &, 36 & 2,50 &, 017 \\
\hline $\mathrm{X} 2$ &, 09 &, 10 &, 13 &, 94 &, 353 \\
\hline $\mathrm{X} 3$ &, 10 &, 05 &, 32 & 2,20 &, 034 \\
\hline
\end{tabular}

Hasil analisis Regresi Linear

Berganda dari Tabel di atas diperoleh persamaan sebagai berikut : $\mathrm{Y}=11,61+$ $0,34+0,9+10+\mathrm{e}$

Berdasarkan persamaan tersebut dapat diketahui bahwa :

a. Konstanta $(\alpha)=11,61$ menunjukkan nilai konstan, jika nilai variabel bebas (Budaya Kerja, Kepuasan Kerja dan Motivasi Kerja $)=0$, maka nilai Kinerja Karyawan (Y) akan sebesar 11,61

b. Koefisien regresi variabel Budaya Kerja sebesar 0,34 menunjukkan bahwa variabel Budaya Kerja memiliki hubungan yang positif terhadap variabel Kinerja Karyawan (Y). Dengan asumsi jika variabel Budaya Kerja meningkat maka variabel Kinerja akan mengalami peningkatan sebesar 0,34.

c. Koefisien regresi variabel Kepuasan Kerja sebesar 0,09 menunjukkan bahwa variabel Kepuasan kerja memiliki hubungan yang positif terhadap variabel Kinerja Karyawan (Y). Dengan asumsi jika variabel Kepuasan Kerja meningkat maka variabel Kinerja akan mengalami peningkatan sebesar 0,09.

d. Koefisien regresi variabel Motivasi Kerja sebesar 0,10 menunjukkan bahwa variabel Motivasi kerja memiliki hubungan yang positif terhadap variabel Kinerja Karyawan (Y). Dengan asumsi jika variabel Motivasi Kerja meningkat maka variabel Kinerja akan mengalami peningkatan sebesar 0,10 .

3. Uji Hipotesis

a. Uji F (Simultan)

Hasil Uji Simultan (Uji F) menunjukkan seberapa besar hubungan dan pengaruh variabel Budaya Kerja (X1), Kepuasan Kerja (X2), dan Motivasi Kerja (X3), secara simultan terhadap variabel Kinerja Karyawan (Y). Pada Uji F, semua variabel bebas dinyatakan signifikan mempengaruhi variabel terikat jika nilai signifikansinya kurang dari 5\% (sig < 0,05). Hasil uji F dapat dilihat pada Tabel berikut :

\section{Tabel 5}

\section{Tabel Uji F}

\begin{tabular}{|l|l|l|l|l|l|}
\hline & $\begin{array}{l}\text { Sum of } \\
\text { Squares }\end{array}$ & Df & $\begin{array}{l}\text { Mean } \\
\text { Square }\end{array}$ & $F$ & Sig. \\
\hline Regression & 85,01 & 3 & 28,34 & 5,07 &, 005 \\
\hline Residual & 201,39 & 36 & 5,59 & & \\
\hline Total & 286,40 & 39 & & & \\
\hline
\end{tabular}

Sumber: Hasil Analisa PSPP (2021)

Berdasarkan Tabel di atas dapat diketahui bahwa nilai sig 0,005 yang mana nilai tersebut lebih kecil dari 0,05. Maka dapat dinyatakan bahwa variabel Budaya Kerja (X1), Kepuasan Kerja (X2), dan Motivasi Kerja (X3) secara simultan berpengaruh signifikan terhadap variabel Kinerja Karyawan (Y). Maka berdasarkan kriteria pengujian hipotesis maka Ha diterima dan Ho ditolak.

b. Uji t (Parsial)

Hasil Uji t (Parsial) menunjukkan seberapa besar hubungan dan pengaruh variabel Kepuasan Budaya Kerja (X1), Kepuasan Kerja (X2), dan Motivasi 
Kerja (X3) secara parsial terhadap variabel Kinerja Karyawan (Y). Pada Uji t, variabel bebas dinyatakan signifikan mempengaruhi variabel terikat jika nilai signifikansinya kurang dari 5\% (sig < 0,05). Hasil Uji t dapat dilihat pada Tabel berikut :

\section{Tabel 6}

Tabel Uji t

\begin{tabular}{|c|c|c|c|c|c|}
\hline \multirow{2}{*}{} & \multicolumn{2}{|c|}{$\begin{array}{c}\text { Unstandardized } \\
\text { Coefficients }\end{array}$} & $\begin{array}{c}\text { Standardized } \\
\text { Coefficients }\end{array}$ & \multirow{2}{*}{$t$} & \multirow{2}{*}{ Sig. } \\
\cline { 2 - 4 } & $\mathrm{B}$ & Std. Error & Beta & & \\
\hline (Constant) & 11,61 & 5,25 &, 00 & 2,21 &, 033 \\
\hline $\mathrm{X} 1$ &, 34 &, 14 &, 36 & 2,50 &, 017 \\
\hline $\mathrm{X} 2$ &, 09 &, 10 &, 13 &, 94 &, 353 \\
\hline $\mathrm{X} 3$ &, 10 &, 05 &, 32 & 2,20 &, 034 \\
\hline
\end{tabular}

Sumber: Hasil Analisa PSPP (2021)

Pada Tabel hasil Uji t di atas, maka dapat diketahui bahwa :

1) Variabel Budaya Kerja (X1) secara parsial berpengaruh terhadap Variabel Kinerja Karyawan (Y) hal ini dilihat dari nilai sig. variabel Kepuasan Kerja (X1) sebesar 0,017 yaitu nilai tersebut lebih kecil dari 0,05 . Artinya variabel Kepuasan Kerja signifikan mempengaruhi peningkatan maupun penurunan Kinerja Karyawan (Y). Berdasarkan kriteria pengujian hipotesis maka $\mathrm{Ha}$ diterima dan Ho ditolak.

2) Variabel Kepuasan Kerja (X2) secara parsial tidak berpengaruh terhadap Variabel Kinerja Karyawan (Y) hal ini dilihat dari nilai sig. variabel Kepuasan Kerja (X2) sebesar 0,353 yaitu nilai tersebut lebih besar dari 0,05 . Artinya variabel Kepuasan Kerja tidak signifikan mempengaruhi peningkatan maupun penurunan Kinerja Karyawan (Y). Berdasarkan kriteria pengujian hipotesis maka $\mathrm{Ho}$ diterima dan Ha ditolak.

3) Variabel Motivasi Kerja (X3) secara parsial berpengaruh terhadap variabel Kinerja Karyawan (Y) hal ini dilihat dari nilai sig. variabel Motivasi Kerja (X3) sebesar 0,034 yaitu nilai tersebut lebih kecil dari 0,05. Artinya variabel Motivasi Kerja mampu mempengaruhi peningkatan maupun penurunan Kinerja

Karyawan (Y) dengan signifikan. Berdasarkan kriteria pengujian hipotesis maka Ha diterima dan $\mathrm{Ho}$ ditolak.

c. Uji Variabel Dominan

Untuk mengetahui variabel bebas yang paling berpengaruh terhadap variabel Kinerja Karyawan (Y) yaitu dapat dilakukan dengan cara membandingkan koefisien regresi (Beta). Variabel bebas yang paling dominan pengaruhnya terhadap variabel Kinerja Karyawan (Y) adalah variabel yang memiliki koefisien regresi (Beta) regresi yang paling besar. Untuk mengetahui variabel bebas dominan, dapat dilihat dari nilai Beta pada Tabel di atas.

Berdasarkan perbandingan nilai Beta dari Tabel diatas, diketahui bahwa variabel Budaya Kerja (X1) memiliki nilai Beta yang paling besar yaitu 0,36. Artinya variabel Budaya Kerja memiliki pengaruh yang lebih besar terhadap variabel Kinerja Karyawan (Y) dibanding variabel Kepuasan Kerja (X2) dan Motivasi Kerja (X3). Hal ini berarti bahwa semakin besar Budaya kerja maka akan semakin menigkatkan Kinerja Karyawan. Berdasarkan kriteria pengujian hipotesis maka Ho diterima dan Ha ditolak.

Dalam penelitian ini dapat diketahui seberapa besar kontribusi variabel Budaya Kerja (X1), Kepuasan Kerja (X2), dan Motivasi Kerja (X3) terhadap variabel Kinerja Karyawan (Y). Melalui koefisien determinasi (R) dengan menggunakan program PSPP, dapat dilihat pada Tabel berikut :

Tabel 7

Determinasi R

\begin{tabular}{|c|c|c|c|}
\hline$R$ & $\begin{array}{c}R \\
\text { Square }\end{array}$ & $\begin{array}{c}\text { Adjusted } R \\
\text { Square }\end{array}$ & $\begin{array}{c}\text { Std. Error of the } \\
\text { Estimate }\end{array}$ \\
\hline 5 &, 30 &, 24 & 2,37 \\
4 &, 30 & \\
\hline
\end{tabular}

Sumber: Hasil Analisa PSPP (2021)

Berdasarkan hasil Uji determinasi (R). pada Tabel di atas diketahui bahwa nilai R Square adalah sebesar 0,30. Artinya 
variabel Budaya Kerja (X1), Kepuasan Kerja (X2), dan Motivasi Kerja (X3), mampu menjelaskan sebesar $30 \%$ pengaruh terhadap variabel Kinerja Karyawan (Y) artinya hubungannya kurang tinggi. Sedangkan sisanya sebesar $70 \%$ dipengaruhi oleh faktor - faktor lain seperti Kompensasi, Disiplin, Stres dan Lingkungan Kerja yang tidak diikutsertakan dalam penelitian ini.

\section{HASIL SESUDAH PANDEMI COVID-19}

1. Uji Asumsi Klasik

a. Uji Normalitas

Uji Normalitas Data bertujuan untuk memastikan data terdistribusi secara normal yaitu adalah tidak ada perbedaan yang signifikan antara data di atas mean dengan data di bawah mean. Uji Normalitas Data dilakukan menggunakan Uji KolmogorovSmirnov. Residual data dapat dinyatakan signifikan atau tidak normal jika nilai Asymp. Sig (2-tailed) kurang dari 0,05 begitu sebaliknya, jika nilai Asymp. Sig (2-tailed) lebih dari 0,05 maka dinyatakan tidak signifikan yang artinya tidak terdapat ketidaknormalan pada residual data.

Tabel 8

Tabel Kolmogorov-Smirnov

\begin{tabular}{|l|l|l|}
\hline \multicolumn{2}{|l|}{} & \multicolumn{1}{|c|}{ RES1 } \\
\hline$N$ & & 40 \\
\hline Normal Parameters & Mean & 0,00 \\
\cline { 2 - 3 } & $\begin{array}{l}\text { Std. } \\
\text { Deviation }\end{array}$ & 2,32 \\
\hline $\begin{array}{l}\text { Most Extreme } \\
\text { Differences }\end{array}$ & Absolute & 0,11 \\
\cline { 2 - 3 } & Positive & 0,08 \\
\cline { 2 - 3 } & Negative & $-0,11$ \\
\hline Kolmogorov-Smirnov Z & 0,72 \\
\hline Asymp. Sig. (2-tailed) & 0,684 \\
\hline
\end{tabular}

Sumber: Hasil Analisa PSPP (2021)

Dari Tabel di atas dapat dilihat bahwa nilai Asymp. Sig. (2-tailed) adalah sebesai 0,684 yang mana nilai tersebut lebih dari 0,05. Dengan demikian berdasarkan dari kriteria pengujian kolmogorov-Smirnov, maka dinyatakan tidak terdapat ketidaknormalan pada residual data. b. Uji Multikolinearitas

Uji Multikolinearitas bertujuan untuk memastikan bahwa didalam suatu model penelitian tidak terdapat variabel bebas yang berkorelasi terlalu erat dengan variabel bebas yang lain. Sebuah penelitian dinyatakan terdapat masalah Multikolinearitas jika korelasi antar variabelnya signifikan $(\operatorname{sign}<0,05)$ dan koefisien korelasinya lebih dari $80 \%$ $(>0,8)$

Tabel 9

Tabel Uji Multikolinearitas (Correlation)

\begin{tabular}{|l|l|l|l|l|}
\hline \multicolumn{2}{|l|}{} & $\mathrm{X} 1$ & $\mathrm{X} 2$ & $\mathrm{X} 3$ \\
\hline $\mathrm{X} 1$ & Pearson Correlation & 1,00 &, 06 &, 11 \\
\hline & Sig. (2-tailed) & &, 729 &, 481 \\
\hline & N & 40 & 40 & 40 \\
\hline X2 & Pearson Correlation &, 06 & 1,00 &,- 06 \\
\hline & Sig. (2-tailed) &, 729 & &, 697 \\
\hline & N & 40 & 40 & 40 \\
\hline X3 & Pearson Correlation &, 11 &,- 06 & 1,00 \\
\hline & Sig. (2-tailed) &, 481 &, 697 & \\
\hline & N & 40 & 40 & 40 \\
\hline
\end{tabular}

Sumber: Hasil Analisa PSPP (2021)

Dari table di atas dapat dilihat bahwa nilai korelasi Variabel Budaya Kerja (X1) dengan Kepuasan Kerja (X2) sebesar 0,06 (6\%) dan Sig (2-tailed) = 0,729, Variabel Budaya Kerja (X1) dengan Motivasi Kerja (X3) sebesar $0,11(11 \%)$ dan Sig (2-tailed) =0,481, Variabel Kepuasan Kerja (X2) dengan Motivasi Kerja (X3) sebesar -0,06 (-6\%) dan Sig (2-tailed) = 0,697.. Berdasarkan hasil analisis tersebut dapat dinyatakan bahwa penelitian ini tidak terdapat masalah multikolinearitas.

c. Uji Heterokedastisitas

Uji Heterokedastisitas bertujuan untuk memastikan bahwa tidak terdapat kesamaan variance residual antara suatu pengamatan ke pengamatan yang lain. Uji heterokedastisitas pada penelitian ini peneliti menggunakan Uji Glejser. Suatu model penelitian dinyatakan memiliki permasalahan heterokedastisitas jika terdapat pengaruh yang signifikan antara masing - masing variabel bebas dengan nilai abselut dari residual datanya atau dengan kata lain, yaitu jika nilai sig. 
kurang dari 0,05 maka dinyatakan terjadi masalah heterokedastisitas. Berikut adalah tabel dari hasil Uji Heterokedastisitas menggunakan Uji Glejser :

Tabel 10

Tabel Uji Glejser

\begin{tabular}{|c|c|c|c|c|c|}
\hline & \multicolumn{2}{|c|}{$\begin{array}{c}\text { Unstandardiz } \\
\text { ed } \\
\text { Coefficients }\end{array}$} & \multirow{2}{*}{$\begin{array}{c}\begin{array}{c}\text { Standardiz } \\
\text { ed } \\
\text { Coefficient } \\
\text { s }\end{array} \\
\text { Beta }\end{array}$} & \multirow[t]{2}{*}{$\mathrm{t}$} & \multirow[t]{2}{*}{$\mathrm{Sig}$} \\
\hline & B & $\begin{array}{c}\text { Std. } \\
\text { Error }\end{array}$ & & & \\
\hline $\begin{array}{c}\text { (Constan } \\
\mathrm{t})\end{array}$ & ,08 & 3,64 & ,00 & $\begin{array}{c}- \\
, 02 \\
\end{array}$ & $\begin{array}{c}98 \\
4 \\
\end{array}$ \\
\hline X1 &,- 17 & , 10 & ,25 & $\begin{array}{c}- \\
1,6 \\
5 \\
\end{array}$ & $\begin{array}{c}, 10 \\
7\end{array}$ \\
\hline $\mathrm{X} 2$ & ,14 & ,06 & ,33 & $\begin{array}{c}2,1 \\
8\end{array}$ & $\begin{array}{c}, 03 \\
5 \\
\end{array}$ \\
\hline X3 & ,04 & ,03 & ,23 & $\begin{array}{c}1,5 \\
5\end{array}$ & 130 \\
\hline
\end{tabular}

Sumber: Hasil Analisa PSPP (2021)

Dari Tabel diatas diketahui bahwa variabel Budaya Kerja (X1) tidak berpengaruh secara signifikan terhadap nilai abselut dari residualnya ( $\operatorname{sig}=$ $0,107>0,05)$, pada variabel Kepuasan Kerja (X2) berpengaruh signifikan terhadap nilai abselut dari residualnya $(\operatorname{sig}=0,035<0,05)$, dan pada variabel Motivasi Kerja (X3) tidak berpengaruh signifikan terhadap nilai abselut dari residualnya $(\operatorname{sig}=0,130>0,05)$. Dari nilai yang telah diperoleh tersebut karena masih ada dua variabel yang tidak signifikan yaitu variabel Budaya Kerja (X1) dan Motivasi Kerja (X3) maka penelitian tersebut dinyatakan tidak terjadi masalah heterokedastisitas.

Analisis Regresi Linear Berganda

Dalam penelitian ini Analisis Regresi Linear Berganda digunakan untuk mengetahui hubungan dan pengaruh variabel Budaya Kerja (X1), variabel Kepuasan Kerja (X2), dan variabel Motivasi Kerja (X3) terhadap variabel Kinerja karyawan (Y) PT. Patriot Intan Abadi Farm Berlian. Persamaan regresi linear berganda adalah sebagai berikut: $\mathrm{Y}=$ $\alpha+\beta 1 \mathrm{X} 1+\beta 2 \mathrm{X} 2+\beta 3 \mathrm{X} 3+\mathrm{e}$
Hasil perhitungan Regresi Linear Berganda dapat dilihat pada Tabel berikut:

Tabel 11

Tabel Uji Regresi Linear Berganda

\begin{tabular}{|c|c|c|c|c|c|}
\hline \multirow{2}{*}{} & \multicolumn{2}{|c|}{$\begin{array}{c}\text { Unstandardized } \\
\text { Coefficients }\end{array}$} & $\begin{array}{c}\text { Standardized } \\
\text { Coefficients }\end{array}$ & \multirow{2}{*}{$t$} & \multirow{2}{*}{ Sig. } \\
\cline { 2 - 6 } & $\mathrm{B}$ & $\begin{array}{c}\text { Std. } \\
\text { Error }\end{array}$ & Beta & & \\
\hline$($ Constant $)$ & 9,12 & 5,83 &, 00 & 2,56 &, 126 \\
\hline $\mathrm{X} 1$ &, 46 &, 16 &, 40 & 2,83 &, 007 \\
\hline $\mathrm{X} 2$ &, 06 &, 10 &, 08 &, 55 &, 585 \\
\hline $\mathrm{X} 3$ &, 11 &, 05 &, 34 & 2,47 &, 019 \\
\hline
\end{tabular}

Berganda dari Tabel di atas diperoleh persamaan sebagai berikut : $\mathrm{Y}=9,12+$ $0,46+0,6+11+\mathrm{e}$

Berdasarkan persamaan tersebut dapat diketahui bahwa :

a. Konstanta $(\alpha)=9,12$ menunjukkan nilai konstan, jika nilai variabel bebas (Budaya Kerja, Kepuasan Kerja dan Motivasi Kerja) $=0$, maka nilai Kinerja Karyawan (Y) akan sebesar 9,12

b. Koefisien regresi variabel Budaya Kerja sebesar 0,16 menunjukkan bahwa variabel Budaya Kerja memiliki hubungan yang positif terhadap variabel Kinerja Karyawan (Y). Dengan asumsi jika variabel Budaya Kerja meningkat maka variabel Kinerja akan mengalami peningkatan sebesar 0,16 .

c. Koefisien regresi variabel Kepuasan Kerja sebesar 0,10 menunjukkan bahwa variabel Kepuasan kerja memiliki hubungan yang positif terhadap variabel Kinerja Karyawan (Y). Dengan asumsi jika variabel Kepuasan Kerja meningkat maka variabel Kinerja akan mengalami peningkatan sebesar 0,10 .

d. Koefisien regresi variabel Motivasi Kerja sebesar 0,05 menunjukkan bahwa variabel Motivasi kerja memiliki hubungan yang positif terhadap variabel Kinerja Karyawan (Y). Dengan asumsi jika variabel Motivasi Kerja meningkat maka variabel Kinerja akan mengalami peningkatan sebesar 0,05 .

2. Uji Hipotesis

a. Uji F (Simultan)

Hasil Uji Simultan (Uji F) menunjukkan seberapa besar hubungan dan pengaruh variabel Budaya Kerja 
(X1), Kepuasan Kerja (X2), dan Motivasi Kerja (X3), secara simultan terhadap variabel Kinerja Karyawan (Y). Pada Uji F, semua variabel bebas dinyatakan signifikan mempengaruhi variabel terikat jika nilai signifikansinya kurang dari 5\% (sig < 0,05). Hasil uji F dapat dilihat pada Tabel berikut :

Tabel 12

Tabel Uji F

\begin{tabular}{|l|l|l|l|l|l|}
\hline & $\begin{array}{l}\text { Sum of } \\
\text { Squares }\end{array}$ & $D f$ & $\begin{array}{l}\text { Mean } \\
\text { Square }\end{array}$ & $F$ & Sig. \\
\hline Regression & 95,43 & 3 & 31,81 & 5,44 &, 003 \\
\hline Residual & 210,55 & 36 & 5,85 & & \\
\hline Total & 305,97 & 39 & & & \\
\hline
\end{tabular}

Sumber: Hasil Analisa PSPP (2021)

Berdasarkan Tabel di atas dapat diketahui bahwa nilai sig 0,003 yang mana nilai tersebut lebih kecil dari 0,05. Maka dapat dinyatakan bahwa variabel Budaya Kerja (X1), Kepuasan Kerja (X2), dan Motivasi Kerja (X3) secara simultan berpengaruh signifikan terhadap variabel Kinerja Karyawan (Y). Maka berdasarkan kriteria pengujian hipotesis maka Ha diterima dan Ho ditolak.

b. Uji t (Parsial)

Hasil Uji t (Parsial) menunjukkan seberapa besar hubungan dan pengaruh variabel Kepuasan Budaya Kerja (X1), Kepuasan Kerja (X2), dan Motivasi Kerja (X3) secara parsial terhadap variabel Kinerja Karyawan (Y). Pada Uji $t$, variabel bebas dinyatakan signifikan mempengaruhi variabel terikat jika nilai signifikansinya kurang dari 5\% (sig < 0,05). Hasil Uji t dapat dilihat pada Tabel berikut :

\section{Tabel 13}

Tabel Uji t

\begin{tabular}{|c|c|c|c|c|c|}
\hline & \multicolumn{2}{|c|}{$\begin{array}{c}\text { Unstandardized } \\
\text { Coefficients }\end{array}$} & $\begin{array}{c}\text { Standardized } \\
\text { Coefficients }\end{array}$ & \multirow{2}{*}{$t$} & \multirow{2}{*}{ Sig. } \\
\cline { 2 - 5 } & $\mathrm{B}$ & $\begin{array}{c}\text { Std. } \\
\text { Error }\end{array}$ & Beta & & \\
\hline (Constant) & 9,12 & 5,83 &, 00 & 2,56 &, 126 \\
\hline $\mathrm{X} 1$ &, 46 &, 16 &, 40 & 2,83 &, 007 \\
\hline $\mathrm{X} 2$ &, 06 &, 10 &, 08 &, 55 &, 585 \\
\hline $\mathrm{X} 3$ &, 11 &, 05 &, 34 & 2,47 &, 019 \\
\hline
\end{tabular}

Sumber: Hasil Analisa PSPP (2021)

Pada Tabel hasil Uji t di atas, maka dapat diketahui bahwa :
1) Variabel Budaya Kerja (X1) secara parsial berpengaruh terhadap variabel Kinerja Karyawan (Y) hal ini dilihat dari nilai sig. variabel Budaya Kerja (X1) sebesar 0,007 yaitu nilai tersebut lebih kecil dari 0,05 . Artinya variabel Budaya Kerja signifikan mempengaruhi peningkatan maupun penurunan Kinerja Karyawan (Y). Berdasarkan kriteria pengujian hipotesis maka Ha diterima dan $\mathrm{Ho}$ ditolak.

2) Variabel Kepuasan Kerja (X2) secara parsial tidak berpengaruh terhadap Variabel Kinerja Karyawan (Y) hal ini dilihat dari nilai sig. variabel Kepuasan Kerja (X2) sebesar 0,585 yaitu nilai tersebut lebih besar dari 0,05. Artinya variabel Kepuasan Kerja tidak signifikan mempengaruhi peningkatan maupun penurunan Kinerja Karyawan (Y). Berdasarkan kriteria pengujian hipotesis maka Ho diterima dan $\mathrm{Ha}$ ditolak.

3) Variabel Motivasi Kerja (X3) secara parsial berpengaruh terhadap variabel Kinerja Karyawan (Y) hal ini dilihat dari nilai sig. variabel Motivasi Kerja (X3) sebesar 0,019 yaitu nilai tersebut lebih kecil dari 0,05 . Artinya variabel Motivasi Kerja mampu mempengaruhi peningkatan maupun penurunan Kinerja Karyawan (Y) dengan signifikan. Berdasarkan kriteria pengujian hipotesis maka $\mathrm{Ha}$ diterima dan Ho ditolak.

c. Uji Variabel Dominan

Untuk mengetahui variabel bebas yang paling berpengaruh terhadap variabel Kinerja Karyawan (Y) yaitu dapat dilakukan dengan cara membandingkan koefisien regresi (Beta). Variabel bebas yang paling dominan pengaruhnya terhadap variabel Kinerja Karyawan (Y) adalah variabel yang memiliki koefisien regresi (Beta) 
regresi yang paling besar. Untuk mengetahui variabel bebas dominan, dapat dilihat dari nilai Beta pada Tabel di atas.

Berdasarkan perbandingan nilai Beta dari Tabel diatas, diketahui bahwa variabel Budaya Kerja (X1) memiliki nilai Beta yang paling besar yaitu 0,40 . Artinya variabel Budaya Kerja memiliki pengaruh yang lebih besar terhadap variabel Kinerja Karyawan (Y) dibanding variabel Kepuasan Kerja (X2) dan Motivasi Kerja (X3). Hal ini berarti bahwa semakin besar Budaya kerja maka akan semakin menigkatkan Kinerja Karyawan. Berdasarkan kriteria pengujian hipotesis maka Ho diterima dan Ha ditolak.

Dalam penelitian ini dapat diketahui seberapa besar kontribusi variabel Budaya Kerja (X1), Kepuasan Kerja (X2), dan Motivasi Kerja (X3) terhadap variabel Kinerja Karyawan (Y). Melalui koefisien determinasi (R) dengan menggunakan program PSPP, dapat dilihat pada Tabel berikut :

\section{Tabel 14}

Determinasi $\mathbf{R}$

\begin{tabular}{|c|c|c|c|}
\hline$R$ & $R$ Square & $\begin{array}{c}\text { Adjusted } R \\
\text { Square }\end{array}$ & $\begin{array}{c}\text { Std. Error of the } \\
\text { Estimate }\end{array}$ \\
\hline, 56 &, 31 &, 25 & 2,42 \\
\hline
\end{tabular}

Sumber: Hasil Analisa PSPP (2021)

Berdasarkan hasil Uji determinasi (R). pada Tabel di atas diketahui bahwa nilai R Square adalah sebesar 0,31. Artinya variabel Budaya Kerja (X1), Kepuasan Kerja (X2), dan Motivasi Kerja (X3), mampu menjelaskan sebesar $31 \%$ pengaruh terhadap variabel Kinerja Karyawan (Y) artinya hubungannya kurang tinggi. Sedangkan sisanya sebesar $69 \%$ dipengaruhi oleh faktor - faktor lain seperti Kompensasi, Disiplin, Stres dan Lingkungan Kerja yang tidak diikutsertakan dalam penelitian ini.

\section{PEMBAHASAN}

Berdasarkan dari hasil pengujian hipotesis dua penelitian yaitu penelitian sebelum dan sesudah Pandemi Covid-19, menunjukkan bahwa terdapat pengaruh secara simultan atau bersama - sama antara variabel Budaya Kerja, Kepuasan Kerja dan Motivasi Kerja terhadap Kinerja Karyawan di Era Pandemi Covid-19 pada PT. Patriot Intan Abadi Farm Berlian Kecamatan Bati - Bati.

Sedangkan untuk pengujian hipotesis yang kedua, pada dua penelitian tersebut yaitu sebelum dan sesudah Pandemi Covid-19 menunjukkan pengaruh secara parsial variabel Budaya Kerja, Kepuasan Kerja dan Motivasi Kerja terhadap Kinerja Karyawan di Era Pandemi Covid-19 pada PT. Patriot Intan Abadi Farm Berlian Kecamatan Bati - Bati. Dalam penelitian ini variabel Budaya Kerja secara parsial berpengaruh signifikan terhadap Kinerja Karyawan dengan nilai Sig. 0,017 pada penelitian sebelum Pandemi Covid-19 dan den nilai Sig. 0,007 pada penelitian sesudah Pandemi Covid-19, variabel Kepuasan Kerja secara parsial tidak berpengaruh signifikan terhadap Kinerja Karyawan, dengan nilai Sig. 0,353 pada penelitian sebelum Pandemi Covid19 dan den nilai Sig. 0,585 pada penelitian sesudah Pandemi Covid-19, dan untuk variabel Motivasi Kerja secara parsial berpengaruh signifikan terhadap Kinerja Karyawan dengan nilai Sig. 0,034 pada penelitian sebelum Pandemi Covid-19 dan den nilai Sig. 0,019 pada penelitian sesudah Pandemi Covid-19, Yang artinya jika variabel Budaya Kerja dan Motivasi Kerja Meningkat, maka Kinerja Karyawan akan mengalami peningkatan juga. Begitu pula sebaliknya, jika variabel Budaya Kerja dan Motivasi Kerja Menurun, Kinerja Karyawan akan mengalami penurunan.

Dari hasil Uji Variabel Dominan, ditemukan bahwa hasilnya tidak sesuai dengan Hipotesis penelitian, dimana variabel bebas yang berpengaruh dominan terhadap variabel Kinerja Karyawan di era Pandemi Covid-19 pada PT. Patriot Intan Abadi Farm Berlian Kecamatan Bati - Bati adalah variabel Budaya Kerja dengan demikian dinyatakan bahwa Ho diterima dan Ha ditolak.

\section{KESIMPULAN}

Berdasarkan hasil penelitian yang telah dilakukan, diperoleh beberapa kesimpulan sebagai berikut : 
1. Budaya Kerja, Kepuasan Kerja, dan Motivasi Kerja berpengaruh secara simultan terhadap Kinerja Karyawan di Era Pandemi Covid-19 pada PT. Patriot Intan Abadi Farm Berlian Kecamatan Bati-Bati.

2. Kepuasan Kerja tidak berpengaruh secara Parsial terhadap Kinerja Karyawan PT. Patriot Intan Abadi Farm Berlian, sedangkan Motivasi Kerja berpengaruh secara parsial terhadap Kinerja Karyawan di Era Pandemi Covid-19 pada PT. Patriot Intan Abadi Farm Berlian Kecamatan Bati-Bati.

3. Budaya Kerja merupakan variabel yang dominan memperngaruhi Kinerja Karyawan di Era Pandemi Covid-19 pada PT. Patriot Intan Abadi Farm Berlian Kecamatan BatiBati.

4. Budaya Kerja karyawan dari pengamatan dilapangan sesudah Pandemi Covid-19 pada PT. Patriot Intan Abadi Farm Berlian Kecamatan Bati-Bati mengalami perubahan pada kebiasan dalam bekerja dan pengaruhnya secara parsial terhadap Kinerja Karyawan meningkat dari penelitian sebelum Pandemi Covid-19. Kepuasan Kerja karyawan dari pengamatan dilapangan sesudah Pandemi Covid-19 pada PT. Patriot Intan Abadi Farm Berlian Kecamatan BatiBati dari sebelum Pandemi Covid-19 mengalami perubahan pada indikator Gaji dan pengaruhnya secara parsial terhadap Kinerja Karyawan dari penelitian sebelum Pandemi Covid-19 sama, yaitu tidak signifikan. Motivasi Kerja karyawan dari pengamatan dilapangan sesudah Pandemi Covid-19 pada PT. Patriot Intan Abadi Farm Berlian Kecamatan Bati-Bati dari sebelum Pandemi Covid-19 tidak mengalami perubahan yang signifikan, tetapi pengaruhnya secara parsial terhadap Kinerja Karyawan meningkat dari penelitian sebelum Pandemi Covid-19.

5. Kinerja Karyawan dari pengamatan dilapangan sesudah Pandemi Covid-19 pada PT. Patriot Intan Abadi Farm Berlian Kecamatan Bati-Bati dari sebelum Pandemi Covid-19 tidak mengalami perubahan yang signifikan.

\section{SARAN}

Berdasarkan kesimpulan yang diperoleh, maka dapat diberi saran sebagai berikut :

1. PT. Patriot Intan Abadi Farm Berlian, perlu mengadakan sosialisasi atau arahan - arahan kepada para atasan karyawan/supervisi yang membahas tentang pentingnya mendengarkan keluhan karyawan, memberi pujian kepada karyawan atas prestasinya, dan memberikan perhatian kepada karyawan atas apa yang mereka kerjakan. karena supervisi lah yang berhadapan langsung dengan para karyawan di lapangan, maka dari itu atasan diharapkan dapat meningkatkan kemampuan supervisi sebagai atasan dilapangan dan memberikan umpan balik yang cukup baik kepada para karyawan. Pada situasi sesudah Covid-19 dalam perihal diterapkannya protokol kesehatan diperusahaan, atasan perlu memberikan solusi agar karyawan kembali merasa gaji yang mereka terima seimbang dengan tanggung jawab pekerjaan mereka seperti, merenovasi kandang semi otomatis menjadi kandang otomatis atau melakukan penambahkan karyawan pada tiap kandang semi otomatis guna meringankan tanggung jawab karyawan pada divisi kandang semi otomatis.

2. Diharapkan untuk peneliti selanjutnya melakukan penelitian tentang variabel lain selain Budaya Kerja, Kepuasan Kerja dan Motivasi Kerja seperti Lingkungan Kerja, Disiplin, Kompensasi dan lain - lain.

\section{DAFTAR PUSTAKA}

A.A. Anwar, Prabu, 2011, Manajemen Sumber Daya Manusia Perusahaan, Remaja Rosdakarya, Bandung

Anaticia, L, 2018, Pengaruh Budaya Kerja (Corporate Culture) terhadap Kinerja Karyawan Bank Aceh Syariah Cabang Banda Aceh (Doctoral dissertation, UIN Ar-Raniry Banda Aceh)

Arianto, D. A. N. 2013. Pengaruh kedisiplinan, lingkungan kerja dan budaya kerja terhadap kinerja tenaga pengajar. Jurnal Economia, 9(2), 191-200 
Arikunto, 1998, Prosedur Penelitian: Suatu Pendekatan Praktek, Rineka Cipta, Jakarta

As'ad Muhammad, 2011, Analisis Kepuasan Sumber Daya Manusia Dan Manfaatnya, Edisi Ketiga, CV. Sinar Harapan, Surabaya

Arianto, D. A. N. 2013, Pengaruh kedisiplinan, lingkungan kerja dan budaya kerja terhadap kinerja tenaga pengajar, Jurnal Economia, 9(2), 191200

Arikunto, 1998, Prosedur Penelitian: Suatu Pendekatan Praktek, Rineka Cipta, Jakarta

Dangnga, M. S., Nuddin, A., Irwan, I. N. P., \& Buhaerah, M, 2018, Influence of Motivation, Communication and Work Culture on the Performance of Agricultural Extension in Parepare. In 2018 3rd International Conference on Education, Sports, Arts and Management Engineering (ICESAME 2018), Atlantis Press

de Alencar, M. D. C., Nääs, I. A., Gontijo, L. A., \& Salgado, D. A, 2007, Effects of labor motivation in poultry production. Brazilian Journal of Poultry Science, 9(4), 249-253

Ghozali, I, 2011, Aplikasi Bisnis Multi Variate Dengan Program IBM SPSS, Badan Penerbit Universitas Diponegoro, Semarang

Hamzah B. Uno, 2009, Indikator - Indikator Motivasi Kerja http://books.google.co.id (diakses tanggal 19 September 2019)

Handoko, T, 2012, Manajemen Personalia Dan Sumberdaya Manusia, Liberty, Yogyakarta.

Harbani, 2010, Motivasi Kerja, PT.Revika Aditama, Jakarta.

Hartanto, Frans M, 2009, Paradigma Baru Manajemen Indonesia, Bandung, Mizan

Hartanto, Eko, https://www.academia.edu/297 93046/CARA MENENTUKAN UKURAN SAMPEL DALAM PENELITIAN KUANTITATIF (diakses tanggal 26 September 2019)
Hasibuan, Sayuti, 2000, Manajemen Sumber Daya Manusia, Pendekatan Non Sekuler, Muhammadiyah Universitas Press and Magister Manager UMS, Surakarta.

Hasibuan Malayu S.P, 2013, Manajemen Sumber Daya Manusia, Bumi Aksara. Jakarta

Herzberg federick , 2011, Organization for european Cooperation (OEEC) Edition 1st, United Kingdom

Kenneth and yuki, 2011, Human resource management (An Experimental Approach international edition, Mc. Graw Hill inc. Singapore.

Kendall, Smith, P.C., LM., \& Hullin, C.L, 2010, The measurement of satisfaction in work and retirement, IL: Rand Mc Nally, Chicago

Lusri, L, 2017, Pengaruh motivasi kerja terhadap kinerja karyawan melalui kepuasan kerja sebagai variabel mediasi pada karyawan PT. Borwita Citra Prima Surabaya, Agora, 5(1)

Mangkunegara, Teknik Memotivasi Karyawan http://117house.blogspot.com (diakses tanggal 18 september 2019)

Matoyo Susilo, 2011, Manajemen Sumber Daya Manusia, BPFE, Yogyakarta.

Marwansyah, Kinerja Menurut Para Ahli, http://Manajemen13.Blogspot.com (diakses tanggal 18 September 2019)

Moeljono, Djokosantoso, (2005), (Cultured) Budaya Organisasi dalam Tantangan, Jakarta, Elex Media.

Nitisemito, 2013, Manajemen Sumberdaya Manusia, PT. Bumi Aksara, Jakarta

Panggaben Mutiara S, 2012, MSDM, Ghalia Indonesia, Jakarta

Purnamasari, D, 2015, Budaya Kerja Pegawai Pada Bagian Organisasi Sekretariat Pemerintah Daerah Kabupaten Donggala. Katalogis, 3(8)

Ravianto, 2012, Manajemen dan Manfaat, Edisi Kelima Belas, Ghalia Indonesia, Jakarta

Rizqina, Z. A., Adam, M., \& Chan, S. (2017). Pengaruh budaya kerja, kemampuan, dan komitmen kerja terhadap kepuasan kerja pegawai serta 
dampaknya terhadap kinerja Badan Pengusahaan Kawasan Perdagangan Bebas dan Pelabuhan Bebas Sabang (BPKS). Jurnal Magister Manajemen, 1(1), 59-69.

Robin Michael, 2013, Human Resources, Edition 6st, United Kingdom

Robbins, Stephen P, 2011, Perilaku Organisasi. Edisi Kesepuluh, PT. Indeks Kelompok Gramedia, Jakarta

Robbins, Stephen P dan Judge, Timothy A, 2015, Perilaku Organisasi. Jakarta: Salemba Empat

Sari, D. R., Jonathan, L. R., \& Latif, I. N. (2016). Pengaruh Budaya Kerja terhadap Kinerja Pegawai pada Badan Kesatuan Bangsa dan Politik Kabupaten Kutai

Timur. Ekonomia, 5(1), 450-455

Sari, O. R., \& Susilo, H, 2018, Pengaruh kepuasan kerja terhadap kinerja karyawan dengan organizational citizenship behavior sebagai variabel intervening (studi pada karyawan PTPN X-Unit Usaha Pabrik Gula Modjopanggoong Tulungagung). Jurnal Administrasi Bisnis, 64(1), 28-35

Simanjuntak, 2012, Faktor Kepuasan Kerja, Edisi Kedtiga, Penerbit CV. Sinar Harapan, Surabaya

Sugiyono, (2011), Metode Penelitian Kuantitatif Kualitatif dan $R \& D$, Alfabeta Bandung.

Stoner, 2013, Manajemen Sekolah Indonesia, PT. Bina Aksara, Jakarta

Sunyoto, Langkah - Langkah Motivasi http://117house.blogspot.com (diakses tanggal 26 September 2019)

Suwatno, (2011). Kinerja Menurut Para Ahli, http://Manajemen13.blogspot.com (diakses tanggal 27 Spetember 2019)

Tika, Prabundu, 2006, Budaya Organisasi dan Peningkatan Kinerja Perusahaan, Bumi Aksara, Jakarta.

Wexley Kenneth, N., dan Gary, A. Yuki, 2011, Perilaku Organisasi dan Psikologi Personalia, PT Rineka Cipta, Jakarta

Wibowo, (2010), Budaya Organisasi, Jakarta, Rajawali Pers.
Yayat Hayati, 2010, Faktor - Faktor Motivasi Kerja http://melvisusantiye.blogspot.com (diakses tanggal 27 September 2019)

Zaglagi, Arief Noviarakhman, 2018, Teknik Analisis Data Kuantitatif Dalam Ilmu Sosial Menggunakan PSPP, Pancasetia, Banjarmasin

Zagladi, Arief Noviarakhman, Fredy Jayen, Sutrisno, dan Melania, 2016, Pedoman Penulisan Skripsi Sekolah Tinggi Ilmu Ekonomi Pancasetia Banjarmasin, Pancasetia, Banjarmasin

Zweell, Michael, 2000, Creating a Culture Of Competance, New York, John Wiley \& Sons, Inc. 